\title{
TEMPERATURE EFFECT ON THE QUALITY OF AIN THIN FILMS
}

\author{
Margarita P. Thompson*, Andrew R. Drews***, Changhe Huang**, Gregory W. Auner** \\ *CH\&MSE Dept., Wayne State University, Detroit, MI 48202 \\ **ECE Dept., Wayne State University, Detroit, MI 48202 \\ ***Physics Dept., Scientific Research Laboratories, Ford Motor Company, Dearborn, MI 48121 \\ Cite this article as: MRS Internet J. Nitride Semicond. Res. 4S1, G3.7 (1999)
}

\begin{abstract}
$\underline{\text { Abstract }}$
AlN thin films were deposited at various substrate temperatures via Plasma Source Molecular Beam Epitaxy. The films were grown on 6H-SiC (0001) substrates. Reflection High Energy Electron Diffraction and Atomic Force Microscopy showed a dramatic change in the surface morphology of the film grown at $640^{\circ} \mathrm{C}$. This is attributed to a change in the growth mechanism from pseudomorphic at lower temperatures to three-dimensional at higher than $640^{\circ} \mathrm{C}$ temperatures. Photoreflectance measurements showed an absorption shift toward $200 \mathrm{~nm}$ as the deposition temperature increases which is attributed to the change in the growth mechanism at higher temperatures. X-Ray Diffraction was unable to conclusively determine the AlN (0002) peak due to a significant diffuse intensity from the SiC (0002) peak. A MIS structure was created by depositing Pt contacts on the film grown at $500^{\circ} \mathrm{C}$. I-V measurements showed that the Pt/AlN contact is Schottky.
\end{abstract}

\section{$\underline{\text { Introduction }}$}

AlN is a group III-V nitride wide bandgap semiconductor. Its bandgap, the largest among the III-V nitrides, gives AlN an array of interesting properties including: high degree of hardness, high thermal and chemical stability, and high thermal conductivity [1-3]. One major area where these properties can find application is in the construction of high-power, hightemperature devices which can operate in harsh conditions. Of particular interest is the possibility for using AIN as an insulator in SiC-based MIS structures [4]. Such devices can operate at temperatures as high as $550^{\circ} \mathrm{C}$ while ordinary Si-based devices fail at around $120^{\circ} \mathrm{C}$. At the same time AlN/SiC-based devices will be less susceptible to radiation damage.

However, prior to designing AlN-based devices, a number of materials issues need to be resolved. Two important problems are: i) finding a technique and optimal growth conditions for depositing stoichiometric AlN films of high purity and low defect density; ii) finding a substrate material which closely matches the lattice parameter and thermal expansion coefficient of AIN.

Here we report a systematic study of the effect of substrate temperature on the crystal quality of AlN thin films grown on $6 \mathrm{H}-\mathrm{SiC}$ (0001) substrates via Plasma Source Molecular Beam Epitaxy (PSMBE). Our understanding of the growth mechanisms of AIN in the PSMBE system at various temperatures is presented.

\section{Experiment}


All AlN films were deposited on pieces from a single 6H-SiC (0001) wafer which was obtained from Advanced Technology Materials in 1994. The substrate was n-type with carrier concentration of $4.8 \times 10^{18} \mathrm{~cm}^{-3}$. The films were deposited on the Si-face of the substrate. $6 \mathrm{H}-\mathrm{SiC}$ was chosen as a substrate for AlN growth because of: (i) their close lattice parameter and thermal expansion coefficient match, and (ii) to study the properties of AlN/SiC MIS structures. Each substrate was ultrasonically degreased for 20 minutes in acetone and methanol in succession, followed by a one-minute etch in $10 \%$ (by volume) $\mathrm{HF}$ for removing any $\mathrm{SiO}_{\mathrm{x}}$ from the surface. Prior to deposition, each substrate was preheated in the PSMBE system above $850^{\circ} \mathrm{C}$ for one hour for degassing. Deposition of AlN films was accomplished using a unique technique developed in our laboratory called Plasma Source Molecular Beam Epitaxy (PSMBE). The PSMBE system has a new and innovative deposition source which includes a magnetically enhanced, r. f. powered hollow cathode, lined with high purity aluminum. A mixture of high purity argon and nitrogen is supplied to the hollow cathode, where a plasma consisting of high energy aluminum, argon, and nitrogen is formed. A flux containing predominantly $\mathrm{Al}^{+}$and $\mathrm{N}^{+}$ ions of energies around $1 \mathrm{eV}$ leaves the hollow cathode source. This flux is further accelerated by negative bias applied to the substrate. The PSMBE system is described in detail elsewhere[5].

AlN films were grown at $440^{\circ} \mathrm{C}, 500^{\circ} \mathrm{C}, 560^{\circ} \mathrm{C}, 640^{\circ} \mathrm{C}$, and $800^{\circ} \mathrm{C}$ using a substrate bias voltage of $-15 \mathrm{eV}$ which is optimum for our PSMBE system. All films had a thickness of approximately $2000 \AA$ as measured by a piezoelectric thickness monitor. The films were characterized in-situ by Reflection High Energy Electron Diffraction (RHEED) and ex-situ by Atomic Force Microscopy (AFM), X-Ray Diffraction (XRD), and optical reflectance. The AFM characterization was performed using a Digital Instruments Nanoscope III operating in contact mode with standard $\mathrm{Si}_{3} \mathrm{~N}_{4}$ tips. The films were characterized by XRD in a Scintag X1 $\theta-\theta$ diffractometer using $\mathrm{Cu}$ radiation. The samples were supported on a zero-background quartz plate and data were collected either in symmetric (Bragg-Brentano) scans or in rocking scans. For optical reflection measurements a Lambda 900 UV/Vis/NIR Spectrometer with range 1803,000 nm was used. For electrical measurements, Pt electrodes were deposited in a dcmagnetron sputtering system on the sample grown at $500^{\circ} \mathrm{C}$. Blanket electrodes were deposited on the bottom surface of the $\mathrm{SiC}$ substrates and top circular contacts with a diameter of $1 \mathrm{~mm}$ were deposited on the films surface through a hard mask. C-V characterization was performed using a HP4192A LF impedance analyzer at frequencies of $1 \mathrm{MHz}$. I-V measurements were performed on a HP4140B pico-ammeter with a dc-voltage source. A heated chuck was used to reach temperatures up to $300 \mathrm{oC}$.

\section{$\underline{\text { Results and Discussion }}$}

AFM revealed a number of scratches on the substrates surface. The depth of the more profound scratches was around $2 \mathrm{~nm}$ as determined by AFM. Following a degassing procedure lasting one hour at $850^{\circ} \mathrm{C}$, RHEED studies of the $6 \mathrm{H}-\mathrm{SiC}$ substrates gave patterns with streaks which is an indication of relatively smooth surfaces with terraces and steps. 

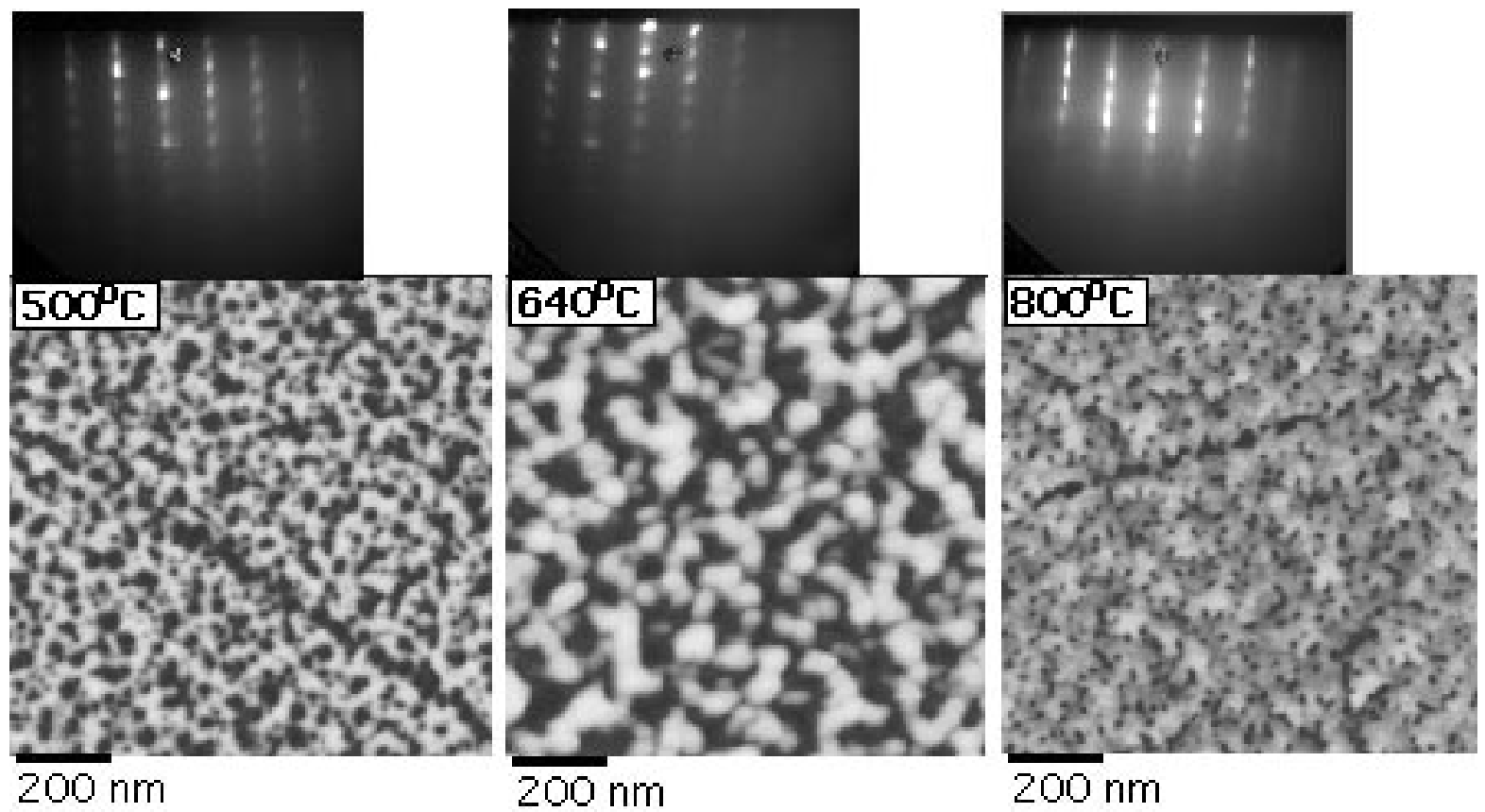

Figure 1. AFM images and RHEED patterns of the films grown at $500^{\circ} \mathrm{C}, 640^{\circ} \mathrm{C}$, and $800^{\circ} \mathrm{C}$. The film deposited at $640^{\circ} \mathrm{C}$ has the greatest roughness and the largest surface features.

As-grown AlN films did not display similar streaking, but rather oblong spots, indicative of facetted islands on the surface. The RHEED pattern from the film deposited at $640^{\circ} \mathrm{C}$ consists of round spots which shows that the surface is rough and the pattern is due to transmission through surface asperities rather than reflection from the surface. Figure 1 shows AFM images and RHEED patterns of the films grown at $500^{\circ} \mathrm{C}, 640^{\circ} \mathrm{C}$, and $800^{\circ} \mathrm{C}$. The film grown at $640^{\circ} \mathrm{C}$ has the greatest roughness and the largest substrate features among all the films. The films grown at temperatures lower than $640^{\circ} \mathrm{C}$ have small surface features very similar to the $500^{\circ} \mathrm{C}$ film. The film deposited at $800^{\circ} \mathrm{C}$ shows unusually shaped features. From the surface analysis one can conclude that at around $640^{\circ} \mathrm{C}$ a change in the growth mechanism occurs. At lower temperatures the depositing species do not have enough energy for lateral movement on the surface. The growth is pseudomorphic which results in smooth but strained films. At around $640^{\circ} \mathrm{C}$ the growth changes to three-dimensional and the film grows in columns. As the deposition temperature increases the films get smoother. This model is in agreement with our previous studies $[5,6]$ on the temperature effect on the quality of AlN films deposited on silicon, sapphire, and Lely grown substrates. 

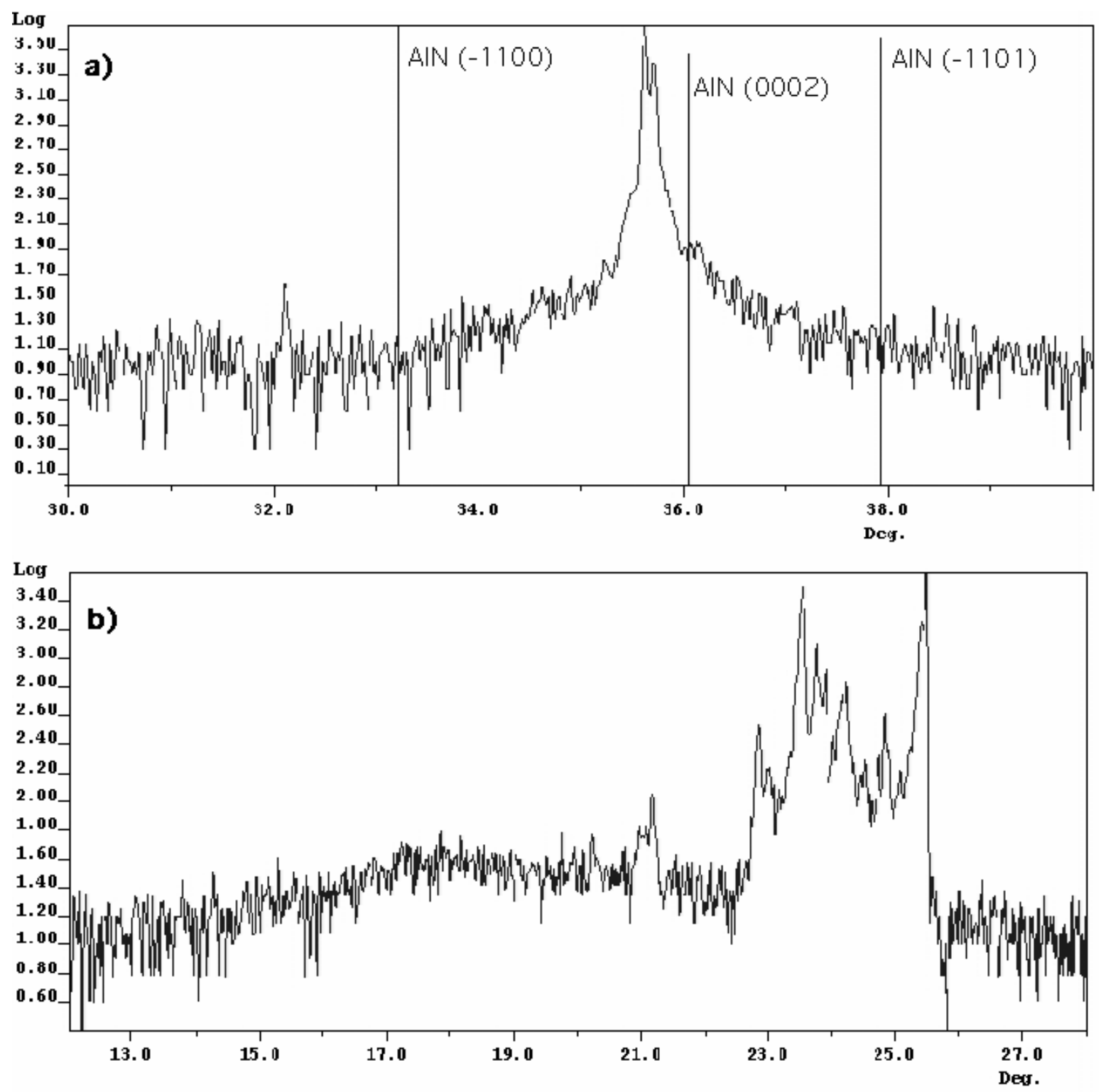

Figure 2. a) A symmetric XRD scan on the film grown at $800^{\circ} \mathrm{C}$ and the standard AlN (-1100), (0002), and (-1101) peaks. b) Rocking scan about the 6H-SiC (0002) peak.

Symmetric XRD scans on all the samples displayed significant intensity from the $\mathrm{SiC}$ (0002) peak near $2 \theta=35.7^{\circ}$ that severely overlaps the AlN (0002) peak, despite the intentional $3.5^{\circ}$ off-cut of the substrates. Figure 2a represents a symmetric scan on the AlN film grown at $800^{\circ} \mathrm{C}$.

An increased intensity around AIN (0002) peak at around $2 \theta=36^{\circ}$ can be observed. However, rocking scans about the $\mathrm{SiC}(0002)$ peak (Fig.2b) showed that the substrates are not single crystals, and typically contain a spread in orientation of about 4 degrees. Figure $2 \mathrm{~b}$ shows a rocking curve about the $6 \mathrm{H}-\mathrm{SiC}(0002)$ peak of another piece from the same wafer illustrating a miscut, larger than the specified one, as well as the wide orientation spread. In addition to the strong crystalline peaks seen in the rocking scans a significant fraction of the $\mathrm{SiC}(0002)$ intensity is diffuse. Due to this diffuse "halo" we are unable to conclusively determine whether we have observed the AlN (0002) peak. However, RHEED data indicates textured AlN growth.

Figure 3 shows photoreflectance measurements for all five films in the wavelength interval between 180 and $800 \mathrm{~nm}$. All reflectance curves are characterized with one large peak 
in the interval 209-230 $\mathrm{nm}$ depending on the growth temperature. The films grown at temperatures lower than $640^{\circ} \mathrm{C}$ indicate a peak reflectivity of $37-40 \%$ in the range $209-216 \mathrm{~nm}$ with a decrease in reflectance at lower wavelengths probably due to absorption at the AlN bandgap. In high quality AlN, absorption should occur at around $200 \mathrm{~nm}$ which corresponds to an energy of $6.2 \mathrm{eV}$. The absorption of the films grown at lower temperatures is shifted to lower wavelengths due to a strained growth. At growth temperatures of $640^{\circ} \mathrm{C}$ and higher, the shift in absorption is observed towards $200 \mathrm{~nm}$ which, to our understanding, is due to a change in the growth mode which causes strain relaxation in the film. This conclusion is in agreement with the surface analysis data discussed above.

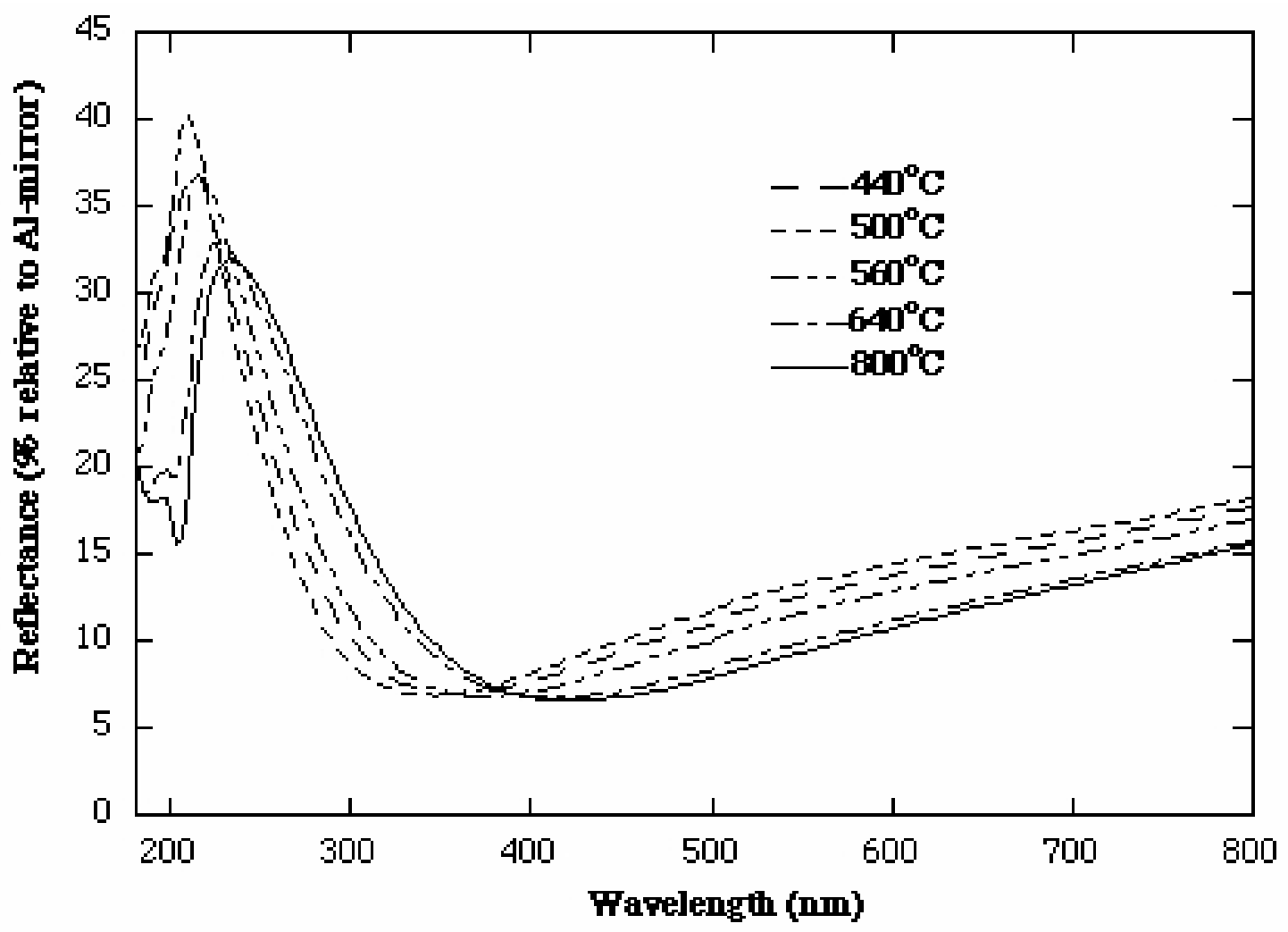

Figure 3. Photoreflectance measurements for all AlN films. 
a)
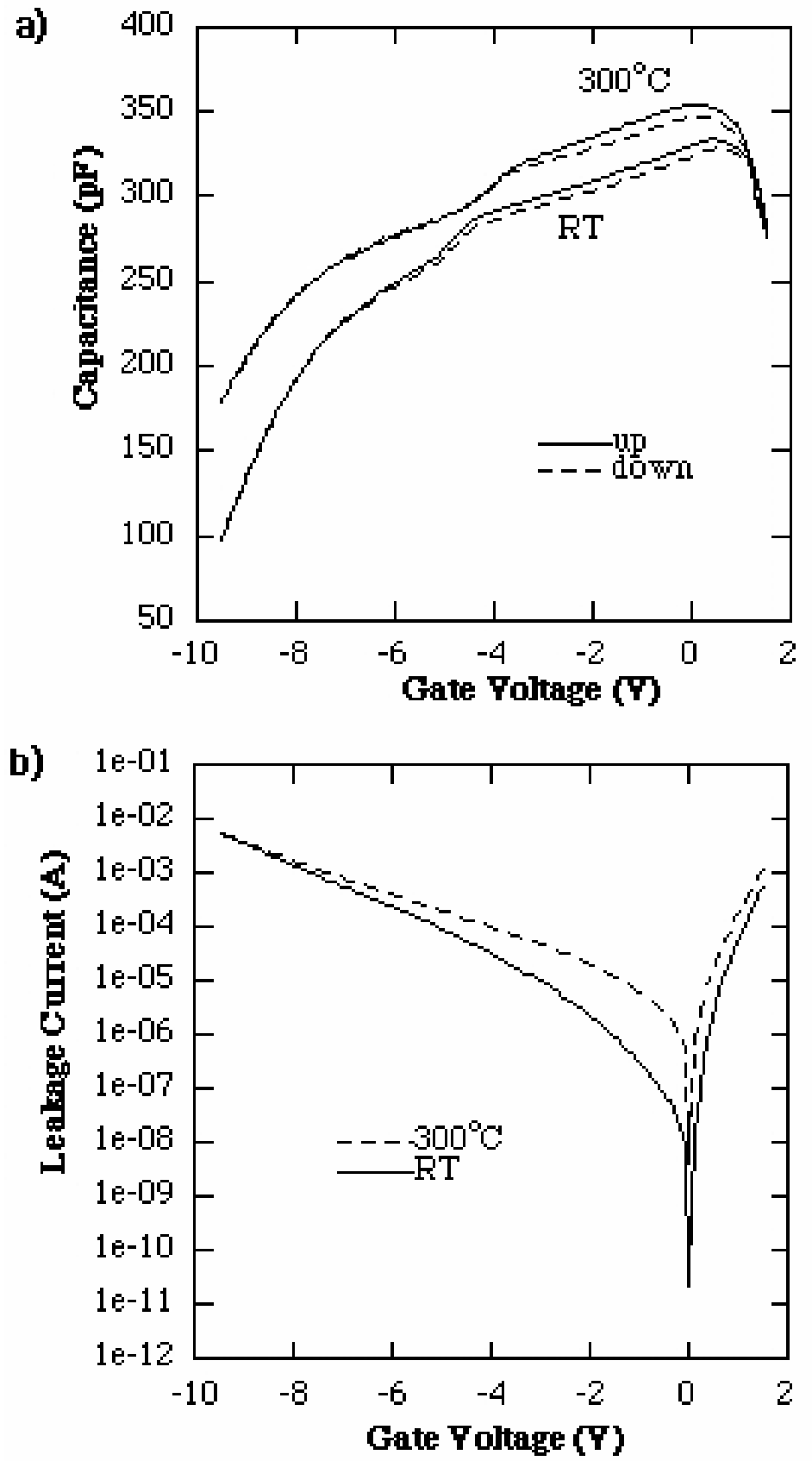

Figure 4. a) Capacitance-Voltage and b) Current-Voltage curves for the AlN film deposited at $500^{\circ} \mathrm{C}$.

Capacitance-voltage $(\mathrm{C}-\mathrm{V})$ and current-voltage $(\mathrm{I}-\mathrm{V})$ measurements were performed at room temperature and $300^{\circ} \mathrm{C}$ on the film grown at $500^{\circ} \mathrm{C}$. Due to the shorting of the contacts on all of the other samples, $\mathrm{C}-\mathrm{V}$ and $\mathrm{I}-\mathrm{V}$ measurements could only be performed on the film grown at $500^{\circ} \mathrm{C}$. We believe that the contact shorting in the other samples is caused by small crystallites on the substrate surface which were visible under optical microscope. This is an example of the critical impact of the substrate surface quality on the performance of device structures. C-V measurements are shown in Figure 4a. A small hysteresis loop was observed both at room temperature and $300^{\circ} \mathrm{C}$, which is an indication of the presence of trapping centers. Another feature of the $\mathrm{C}-\mathrm{V}$ curve is the presence of a shoulder at room temperature and $300^{\circ} \mathrm{C}$. However, at $300^{\circ} \mathrm{C}$ this shoulder is shifted toward lower voltages. Figure $4 \mathrm{a}$ also shows that the 
$\mathrm{C}-\mathrm{V}$ curve measured at $300^{\circ} \mathrm{C}$ is shifted in the negative bias direction compared to the curve obtained at room temperature. This observation is similar to that reported by Tin et al. [4]. They attribute this shift to the activation of fixed positively charged states in the AlN layer at the film/substrate interface at elevated temperatures. The I-V characteristics at room temperature and $300^{\circ} \mathrm{C}$ are shown in Figure $4 \mathrm{~b}$. The sample has high leakage currents at both temperatures. Although the leakage current at $300^{\circ} \mathrm{C}$ is slightly higher it did not damage the sample. The I-V curves were repeatable even after multiple cycles of heating to $300^{\circ} \mathrm{C}$ and cooling back to room temperature. The high leakage current as well as the hysteresis loop in the $\mathrm{C}-\mathrm{V}$ curves may be due to high defect density in the film grown at $500^{\circ} \mathrm{C}$. RHEED, AFM and optical reflection measurements confirm that the defect density of this film is high. In addition, the SiC crystallites protrude through the film to within a very close distance to the contacts. Thus, the distance between a contact and the $\mathrm{SiC}$ substrate at the points of protrusion could be only a few hundred $\AA$ which may partly account for the high leakage current. The defect density in the samples grown at higher temperatures is expected to be smaller and we would expect better $\mathrm{C}-\mathrm{V}$ and I-V characteristics.

\section{Conclusions}

A systematic study of the effect of deposition temperature on the AlN crystalline quality was performed. Surface analysis including RHEED and AFM showed that around $640^{\circ} \mathrm{C}$ the growth mode changes from pseudomorphic to three dimensional. Temperatures higher than $640^{\circ} \mathrm{C}$ tend to give smoother films. Due to a high diffuse intensity of the SiC (0002) peak, XRD scans could not conclusively determine that the higher intensity at $2 \theta=36^{\circ}$ is due to the AlN (0002) peak. Photoreflectance measurements showed an absorption shift toward $200 \mathrm{~nm}$ as the deposition temperature of the films increased. Electrical measurements on the film deposited at $500^{\circ} \mathrm{C}$ showed that the Pt/AlN contacts are Schottky. $\mathrm{C}-\mathrm{V}$ measurements showed a small hysteresis loop both at room temperature and $300^{\circ} \mathrm{C}$. The $\mathrm{C}-\mathrm{V}$ curve at $300^{\circ} \mathrm{C}$ was shifted toward lower negative voltages.

\section{$\underline{\text { Acknowledgments }}$}

The authors wish to acknowledge support for this research by the National Science Foundation (Grant No. DGE-9870720) and the Institute for Manufacturing Research at WSU. We would also like to acknowledge Dr. Guang-Zhao Mao, Jie Xu, and Quiang Zhao for their support and contribution in conducting the experiments.

\section{$\underline{\text { References }}$}

1. S. Strite and H. Morkoç, J. Vac. Sci. Technol. B 10 (1992) 1237

2. J. H. Edgar, J. Mater. Res. 7 (1992) 235

3. Robert F. Davis, Proceedings of the IEEE 79 (1991) 702

4. C. C. Tin, Y. Song, T. Isaacs-Smith, J. Electron. Mater. 26 (1997) 212

5. G. W. Auner, T. D. Lenane, F. Ahmad, R. Naik, P. K. Kuo, Z. Wu, "Epitaxial growth of AlN by plasma source molecular beam epitaxy", M. A. Prelas et al., "Wide Band Gap Electronic Materials" 329, (1995) Kluwer Academic Publishers, Printed in Netherlands

6. M. Lekova, G. W. Auner, F. Jin, R. Naik, V. Naik, Mat. Res. Soc. Symp. Proc. 449 (1997) 245 